\title{
Proses Desain Kursi dengan Memanfaatkan Modul Silinder dari Bonggol Jagung
}

\author{
${ }^{1}$ Priskila Indah Saptorini, ${ }^{2}$ Andry Masri
}

1. Jurusan Desain Produk, Fakultas Seni Rupa dan Desain, ITENAS, Bandung.

2. Jurusan Desain Produk, Fakultas Seni Rupa dan Desain, ITENAS, Bandung.

Email : ${ }^{1}$ priskilaindahs@gmail,com 2 andrymasri@gmail.com

\section{ABSTRAK}

Salah satu hasil dari eksplorasi bonggol jagung adalah modul berbentuk silinder. Pada penelitian ini modul berbentuk selinder akan dimanfaatkan sebagai komponen pada kursi, sehingga akan dilakukan pencarian teknik yang tepat dan desain yang sesuai sehingga dapat menjadi suatu kesatuan yang kuat untuk dijadikan kursi. Dengan demikian tujuan pada proses desain ini adalah menghasilkan desain kursi yang tepat dan sesuai dengan teknik dalam memanfaatkan modul bonggol jagung berbentuk silinder, mendapatkan nilai yang kompromis dari kebaruan dengan teknik perakitan modul yang harus mampu berfungsi dengan baik. Peran penelitian untuk Proyek Desain 5 dan Kerja Profesi adalah menemukan dan menguji material bonggol jagung yang dianyam dengan tali sebagai komponen alas duduk sebuah kursi. Metode penelitian yang dilakukan adalah eksperimen. Hasil penelitian menunjukkan adanya kebaruan dan diperoleh produk berbahan baku bonggol jagung dalam bentuk selinder yang dapat berfungsi baik sebagai komponen kursi.

Kata kunci: Bonggol, Silinder, Sarana duduk

\section{PENDAHULUAN}

Proses desain merupakan suatu rangkaian metodologi dalam membuat sebuah desain, proses desain juga biasa disebut sebagai design thinking. Proses desain meliputi proses perencanaan desain yang terdiri dari latar belakang hingga mendapatkan suatu masalah yang kemudian dianalisis untuk mendapatkan solusi desain yang tepat.

5 stages in the design thinking process: (1) Emphatize, is to gain an empathic understanding of the problem you are trying to solve. Emphaty allows design thinkers to set aside their own assumptions about the world in order to gain insight into users and their needs. (2) Define, is determining the problem to be discussed and helping to gather great ideas to solve the problem or allow users to solve the problem themselves with a minimum level of difficulty.(3) Ideate, brainstorming to find the best way to solve a problem. (4) Prototype, the prototype was carried out as an experimental phase the aim was to identify the best solution for each problem identified during the first three stages. (5) Test, conduct testing to redefine the problem and inform the user's understanding and empathy. (Siang n.d.)

Proses eksplorasi material berbeda dengan proses desain pada umumnya, proses diawali oleh (1) Pengenalan Material, pada tahap pengenalan ini, dilakukan banyak sekali eksperimen-eksperimen berupa tindakan (perlakuan) yang bersifat fisik atau kimia. (2) Eksperimen Lanjutan, pada tahap ini, satu material akan menerima beberapa perlakuan dengan urutan tertentu. (3) Evaluasi Alternatif, diperlukan pengendalian jarak antara material dan pelaku sebagai upaya melihat material dengan jernih sebagai objek yang diolah. (4) Optimalisasi Dimensi dan Struktur, tahap pencarian struktur dan dimensi yang optimal yang dapat diperoleh oleh material guna memperoleh satu bentukan. (5) Studi Detail Desain, tahap pertimbangan mengenai detail desain. Jika aspek struktural, dimensi dan fisik sudah menghasilkan sesuatu yang dapat dinilai baik, maka tahap selanjutnya adalah melakukan optimalisasi terhadap bentuk tiga dimensional tersebut. (Andry and Pasaribu 2018)
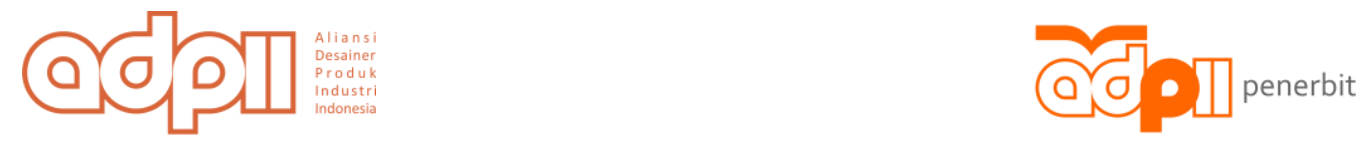
Proses desain secara umum dan secara eksplorasi material memiliki persamaan pada tahap define hingga prototyping, sehingga proses desain yang akan dilakukan penulis dalam memanfaatkan modul bonggol jagung berbentuk silinder akan dimulai dari tahap (1) Ideate, yaitu brainstorming. (2) Prototyping, membuat model awal. (3) Test, prototype awal diuji sesuai kriteria, dari hasil analisis kemungkinan akan mengungkap wawasan yang mendefinisikan kembali masalah yang baru (tahap define) dan membuka ide-ide baru (tahap ideate).

Jagung sendiri merupakan kebutuhan pangan utama bagi masyarakat, sehingga memiliki nilai permintaannya yang tinggi, oleh karenanya pemerintah menjadikan perkembangan jagung sebagai prioritas utama. Sisa pengolahan industri pertanian pada jagung akan menghasilkan limbah berupa bonggol jagung yang jumlahnya akan terus bertambah seiring dengan peningkatan kapasitas produksi (Mahardhika 2014)

Dengan adanya peluang lain terhadap bonggol jagung, diharapkan juga bahwa limbah bonggol jagung dapat diolah juga menjadi kerajinan tangan oleh seluruh masyarakat di kalangan apapun. Didasarkan pada hasil penelitian disertasi yang sedang dilakukan oleh Andry, pada tataran konseptual diperoleh kesimpulan bahwa ekplorasi material sesungguhnya dapat diterapkan pada masyarakat umum, yang tidak memiliki latar belakang akademik Seni Rupa dan Desain. (A. S. Andry 2015). Dalam menfaatkan limbah bonggol jagung yang ada, telah dilakukan eksplorasi yang menghasilkan banyak alternatif berupa modul. Modul yang dihasilkan akan diolah dan dikembangkan agar potensi dari bonggol jagung terlihat dan dapat dimanfaatkan sebagai material sebuah produk. 'Design by doing' adalah pendekatan desain yang akan diterapkan dalam proses pencarian potensi material dan perancangan produk (Dedy 2011)

Hasil dari pengolahan dan pengembangan potensi bonggol jagung menunjukkan bahwa modul silinder bonggol jagung memiliki potensi sebagai material pembuatan produk, sehingga modul yang difokuskan adalah modul silinder yang akan dimanfaatkan sebagai komponen sebuah sarana duduk. Modul tersebut akan dianyam bersama dengan tali, sehingga dapat disebut sebagai kerajinan tangan, karena prosesnya tidak akan membutuhkan mesin. Fokus utama dari kerajinan adalah bahwa pelakunya melibatkan keahlian tangan secara langsung yang tinggi, melebihi keterampilan penggunaan mesin (Andry and Pasaribu 2018)

\section{METODE}

Proses desain berawal dari brainstorming untuk mencari teknik dan metode anyaman bonggol jagung dengan tali dan untuk membuat alternatif desain kerangka kursi.

Eksperimen juga dilakukan untuk mencari teknik yang tepat untuk anyaman. Setelah metode anyaman dan desain kerangka kursi didapatkan, proses selanjutnya adalah mencari teknik jointing anyaman pada kerangka kursi, proses ini juga mempengaruhi detail pada desain kerangka kursi.

Proses selanjutnya adalah prototyping awal. Prototype kemudian diuji coba ketahanan serta kekuatan bonggol jagung, hasil uji coba akan dianalisa sebagai aspek ergonomi pada kursi. Analisis juga dilakukan pada desain kursi, hasil analisa pada desain kursi akan menjadi acuan sebagai pengembangan desain selanjutnya.

Proses terakhir merupakan prototype akhir, desain prototype akhir dibuat berdasarkan hasil test, uji coba, dan analisa prototype awal.
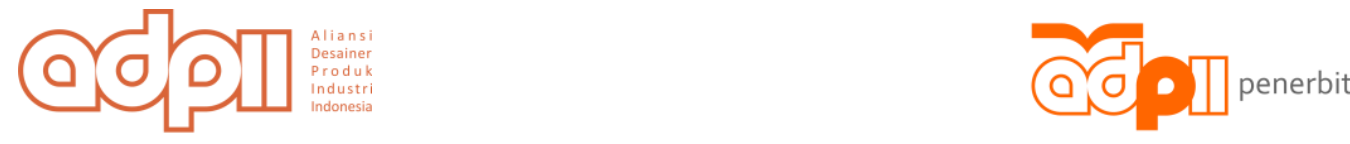


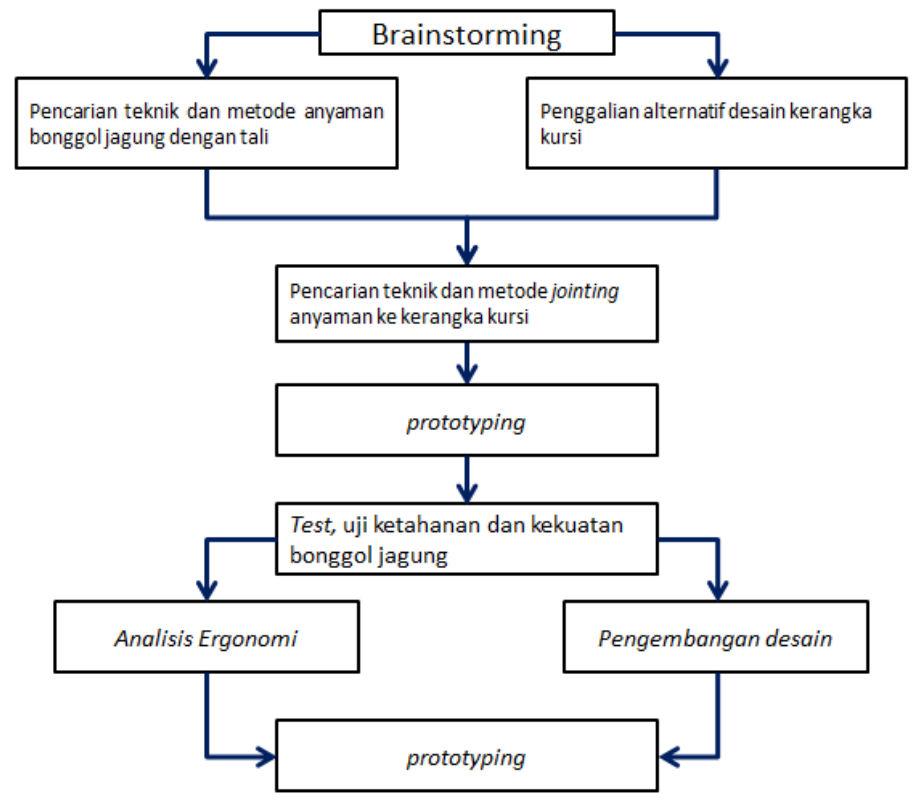

Bagan. 1 Proses desain yang dilaksanakan

\section{PEMBAHASAN}

Pada hasil penelitian terdahulu terdapat beberapa hasil eksplorasi bonggol jagung yang dapat dijadikan sebagai modul sebagai bahan/bentuk dasar pembuatan produk yaitu berupa plat, dan silinder.

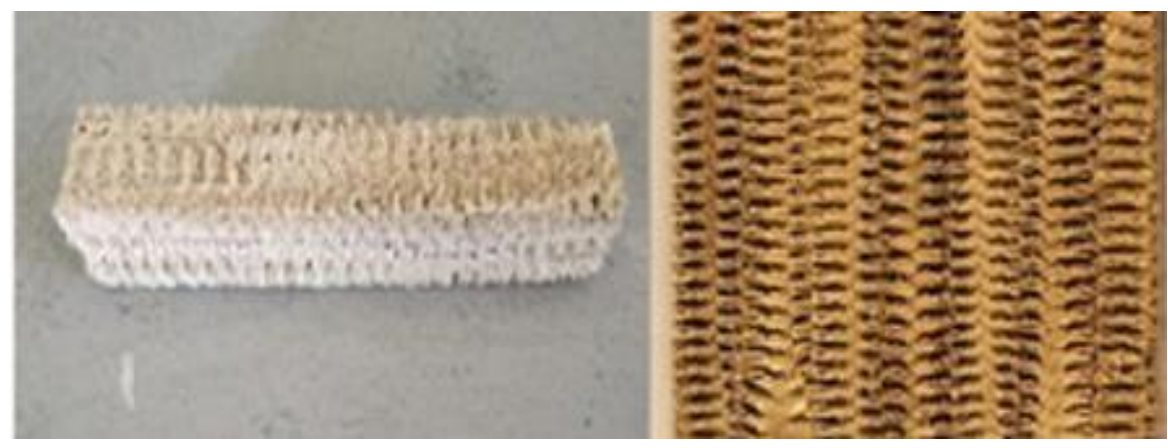

Gambar 1. Bahan Baku dan Modul Berbentuk Plat

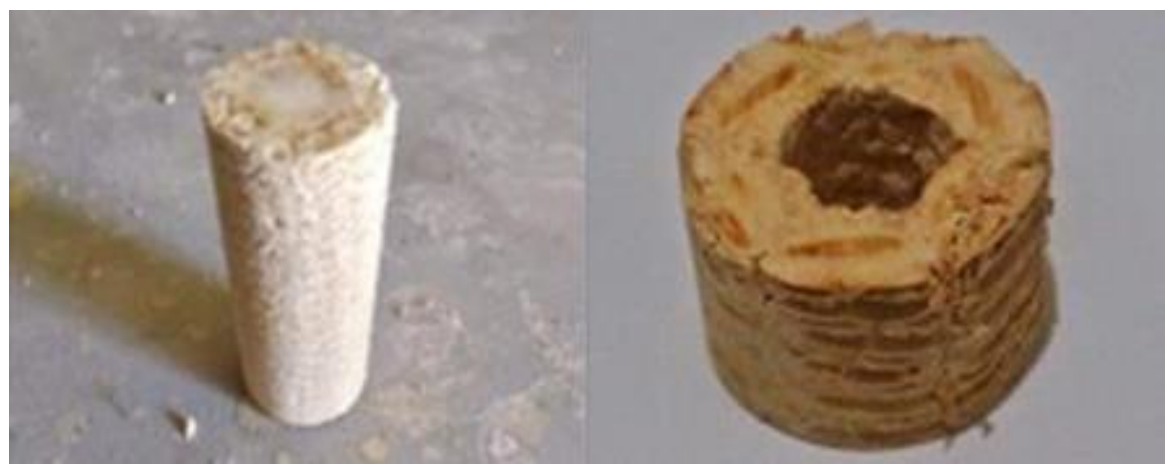

Gambar 2. Bahan Baku dan Modul Berbentuk Silnder
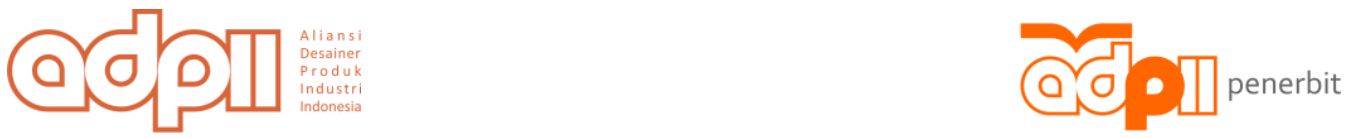


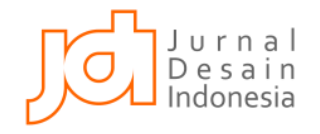

Modul silinder dipilih menjadi modul yang digunakan sebagai komponen utama pada kursi, dan ditetapkan sebagai komponen alas duduk pada kursi. Bonggol jagung berbentuk silinder tersebut memiliki diameter yang beragam dan dapat memiliki panjang 1,2,3, dan $5 \mathrm{~cm}$.

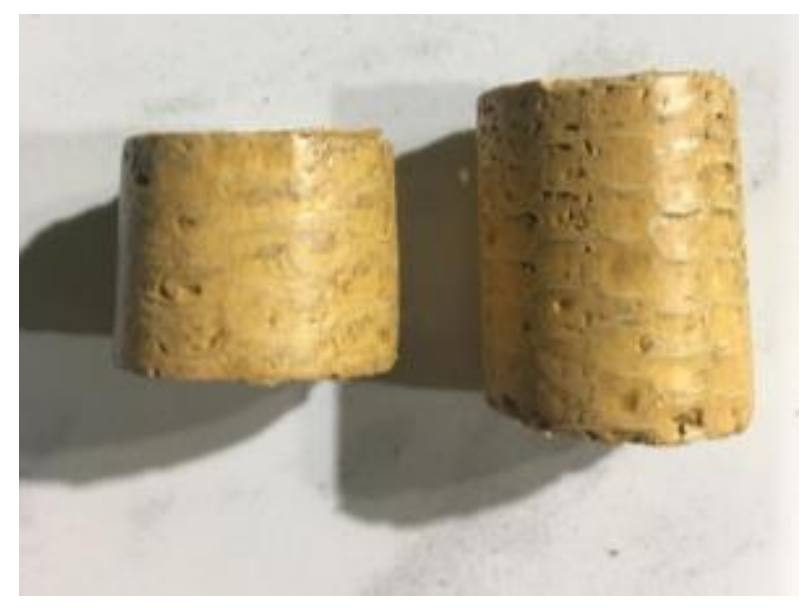

\section{Gambar 3. Modul Silinder Berukuran 2 dan $3 \mathrm{~cm}$}

Dengan adanya potensi modul silinder untuk dijadikan alas sarana duduk, tali dipilih menjadi material dukungan untuk modul bonggol jagung. Dengan demikian, eksperimen pertama yang dilakukan adalah mencari teknik dan metode anyaman modul silnder menggunakan beberapa alternatif tali. Analisis hasil eksperimen ditekankan pada kekuatan dan ketepatan teknik anyaman serta jenis tali yang dipakai.

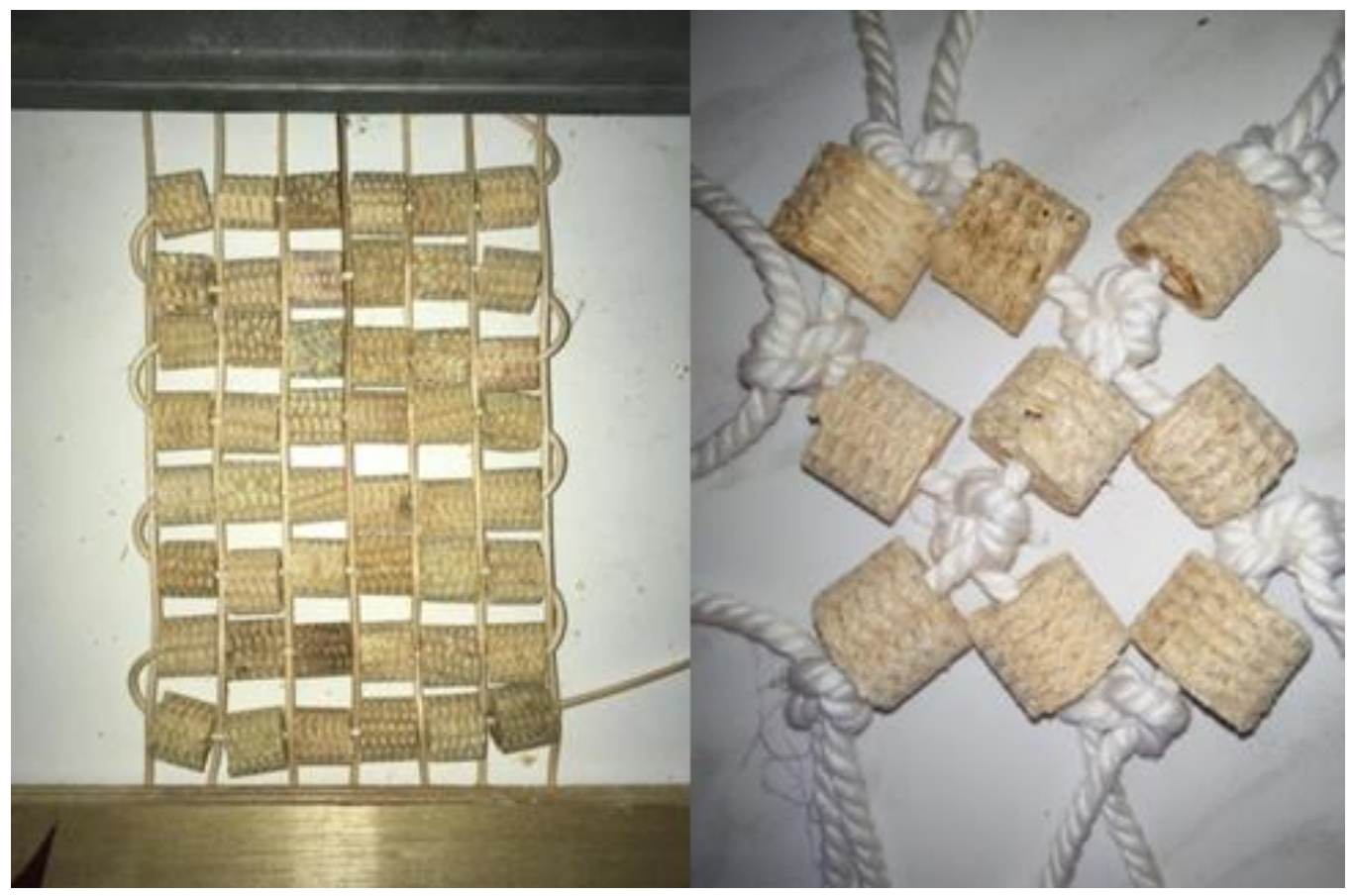

Gambar 4. Eksperimen Rotan (Kiri) dan Tali Pramuka (Kanan)
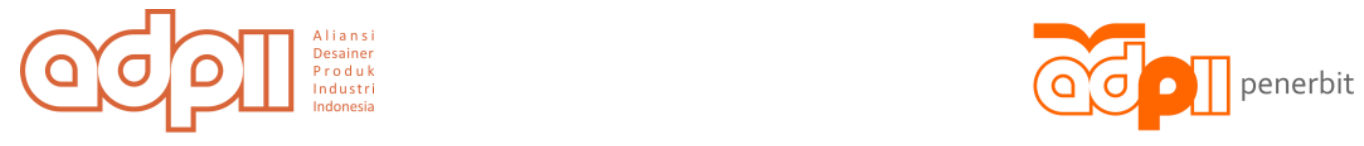
Jurnal Desain Indonesia Volume 02, nomor 01 - Aliansi Desainer Produk Industri Indonesia

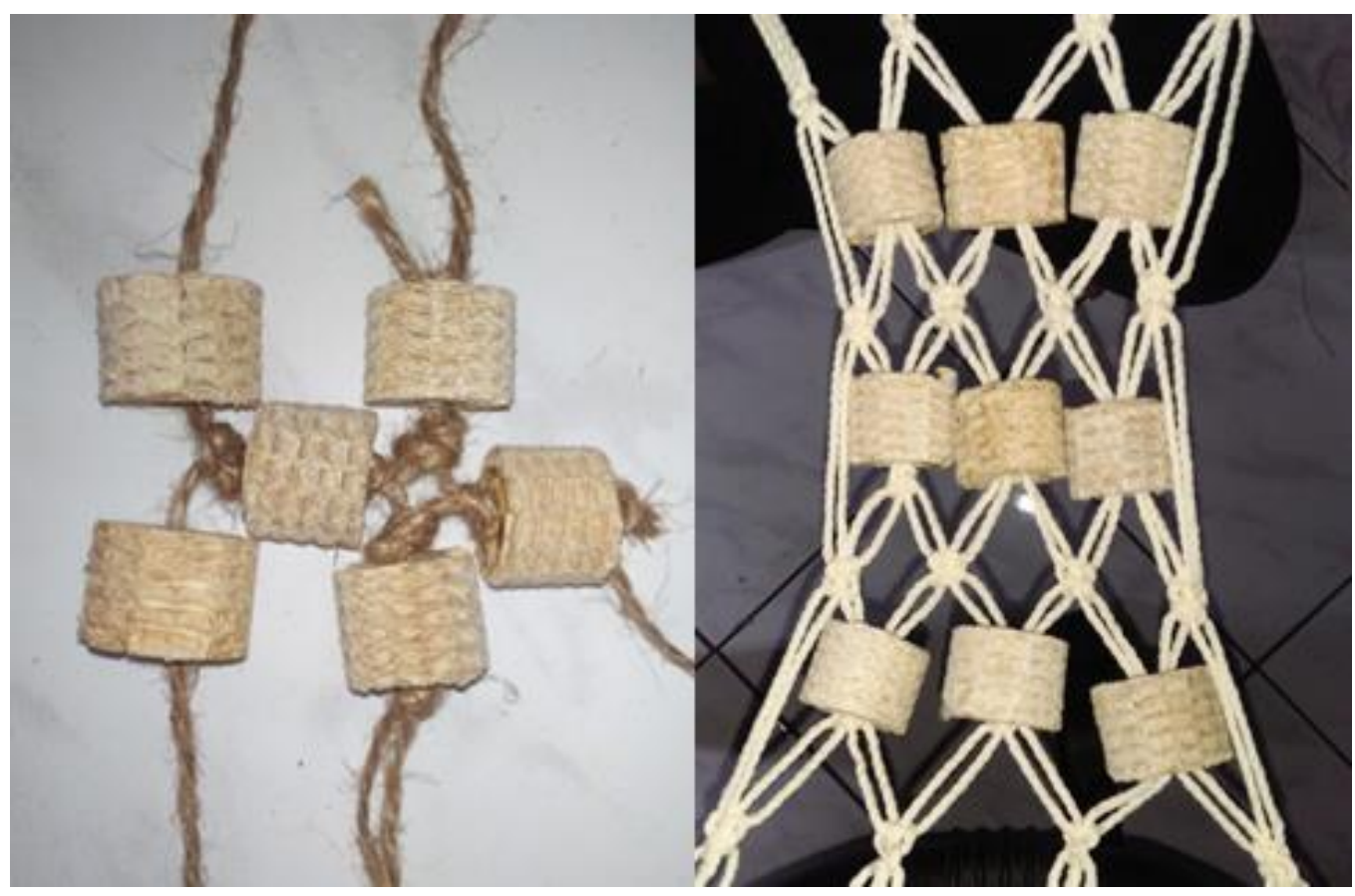

Page | 5

Gambar 5. Eksperimen Tali Goni (Kiri) dan Tali Macrame (Kanan)

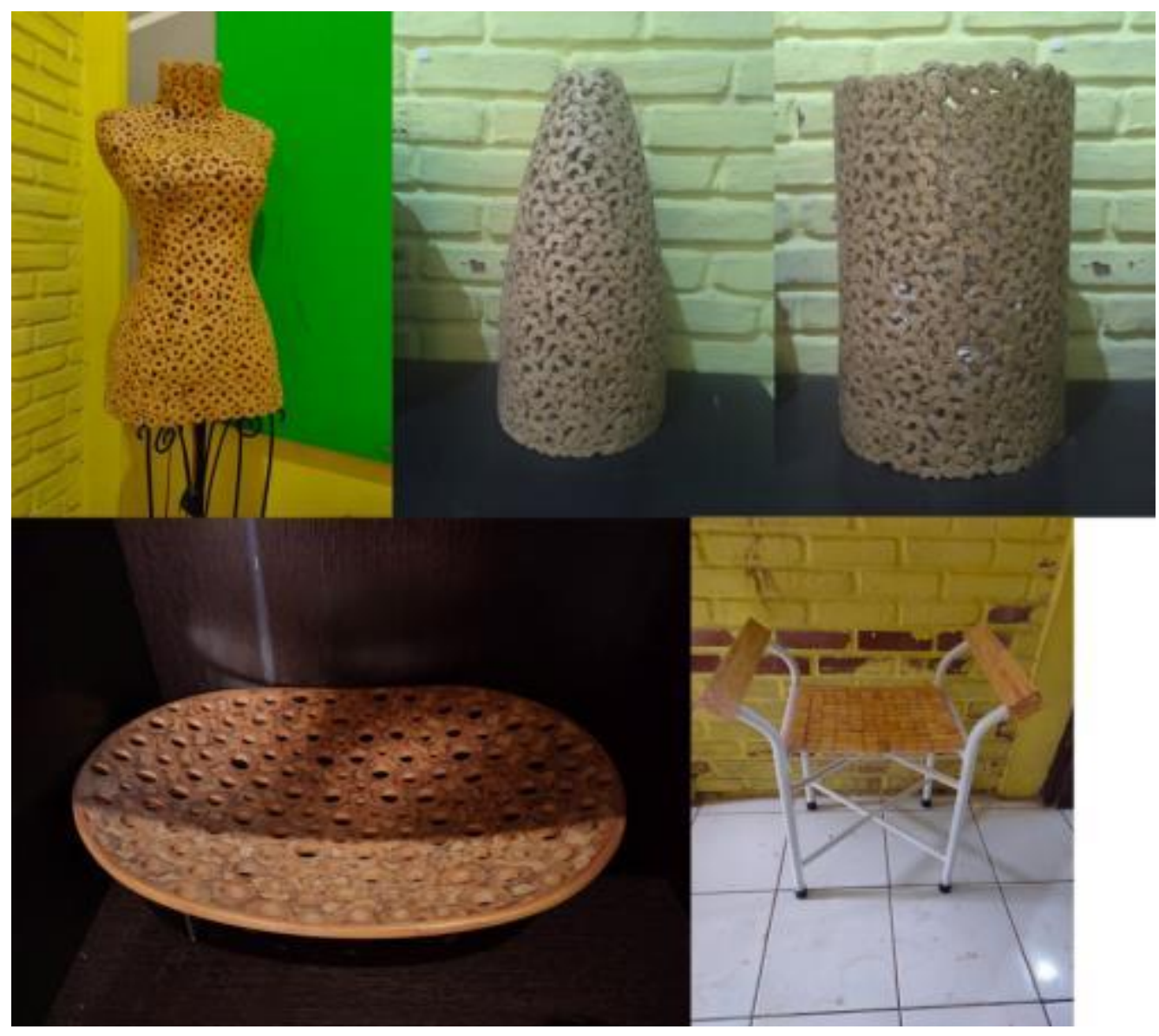

Gambar 6. Produk dari Modul Silinder dari CV. Craftindo Kreasi

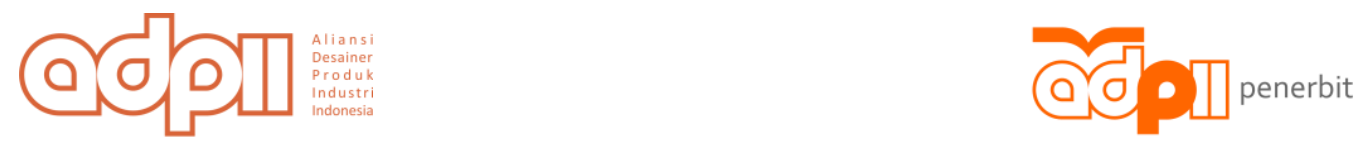


Alternatif desain kerangka kursi harus dilakukan agar sesuai dengan teknik anyaman dan memiliki kecocokan jika dipadukan dengan alas duduk bermodul bonggol jagung. Desain kursi tidak terpatok dari jenis dan kriteria apapun.
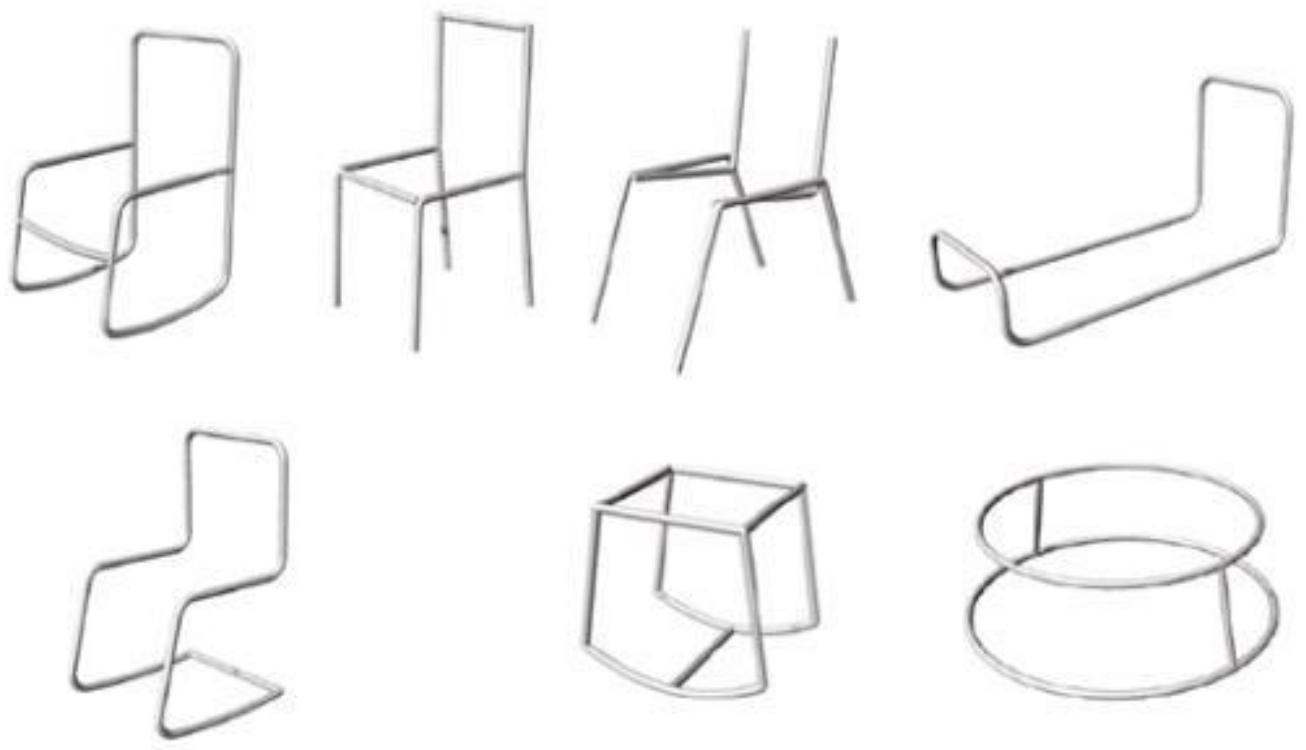

\section{Gambar 7. Alternatif Desain Rangka berbasis Hollow}
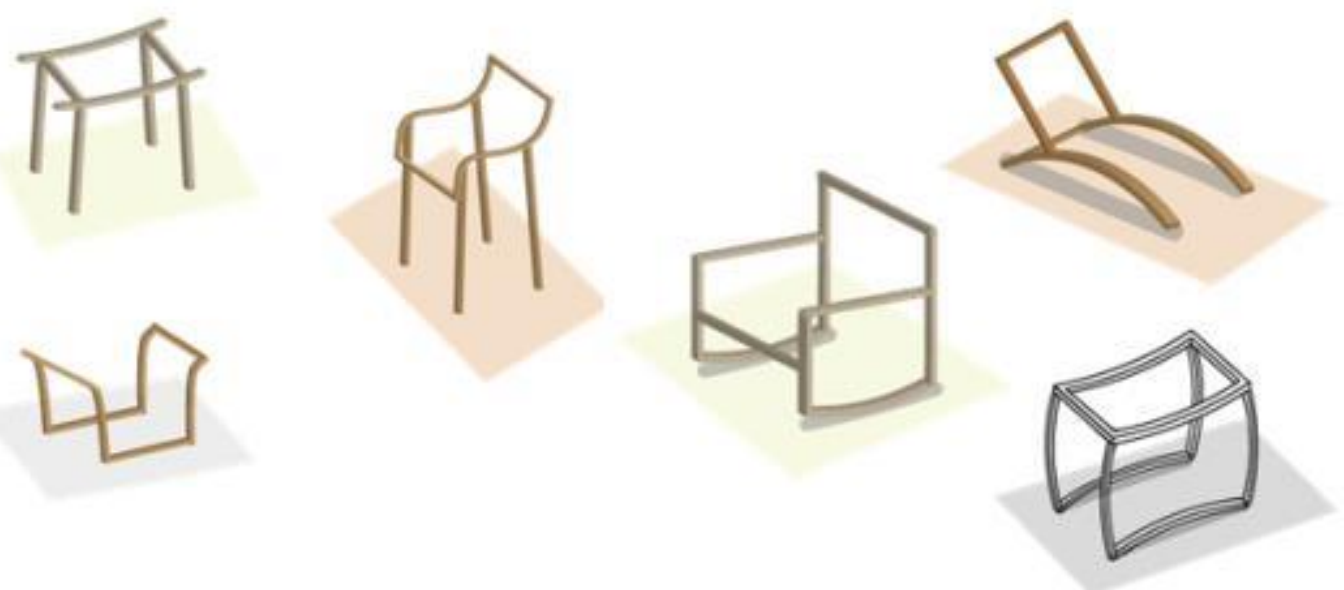

Gambar 8 Alternatif rangkat berbasis kayu.
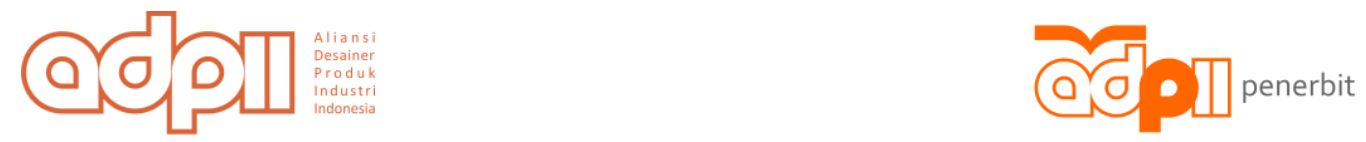

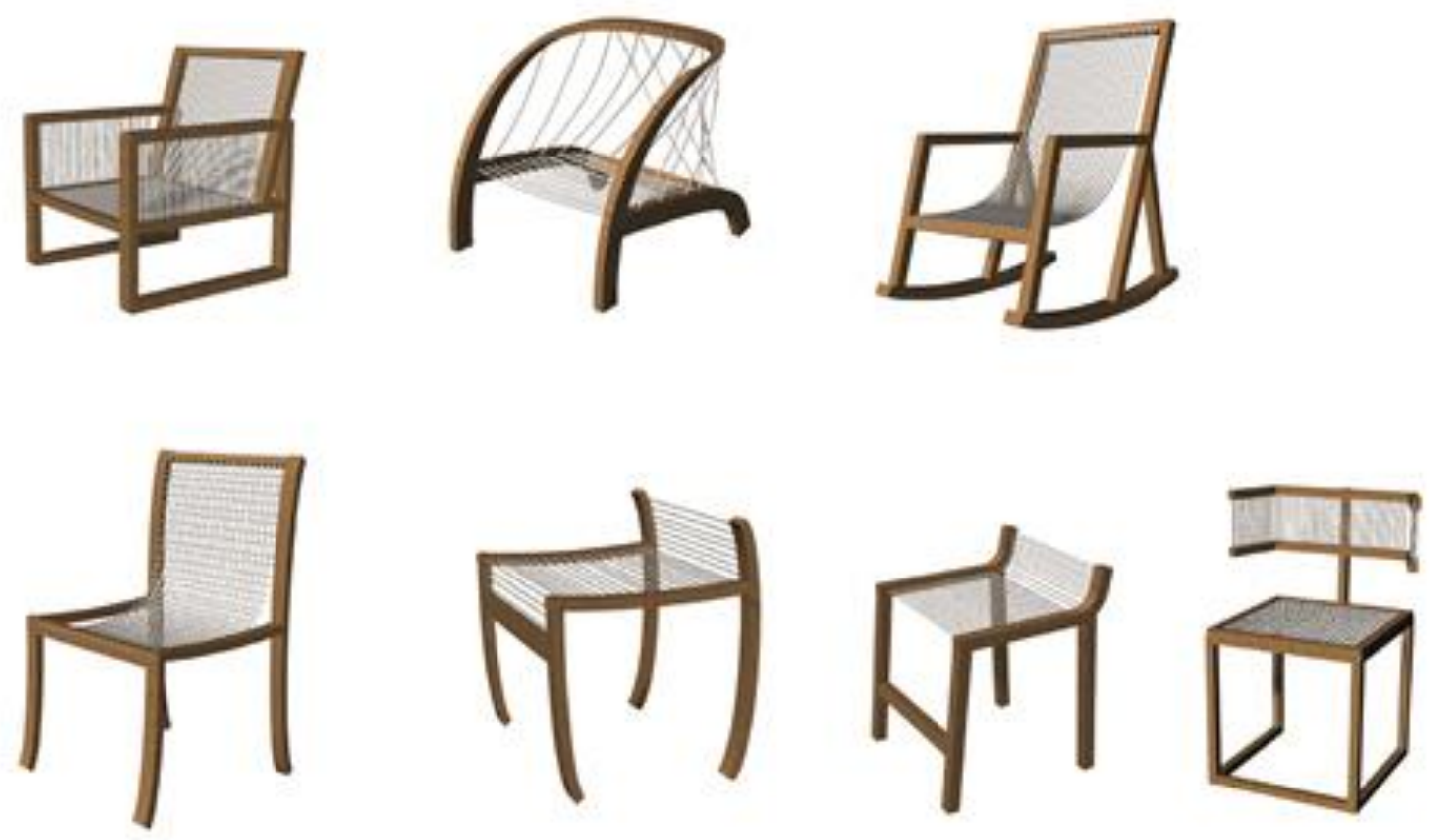

\section{Gambar 9. Alternatif Desain}

Eksperimen dilakukan untuk mencari teknik jointing anyaman untuk diterapkan pada kerangka kursi. Desain kerangka kursi yang terpilih diberi detail untuk jointingnya.
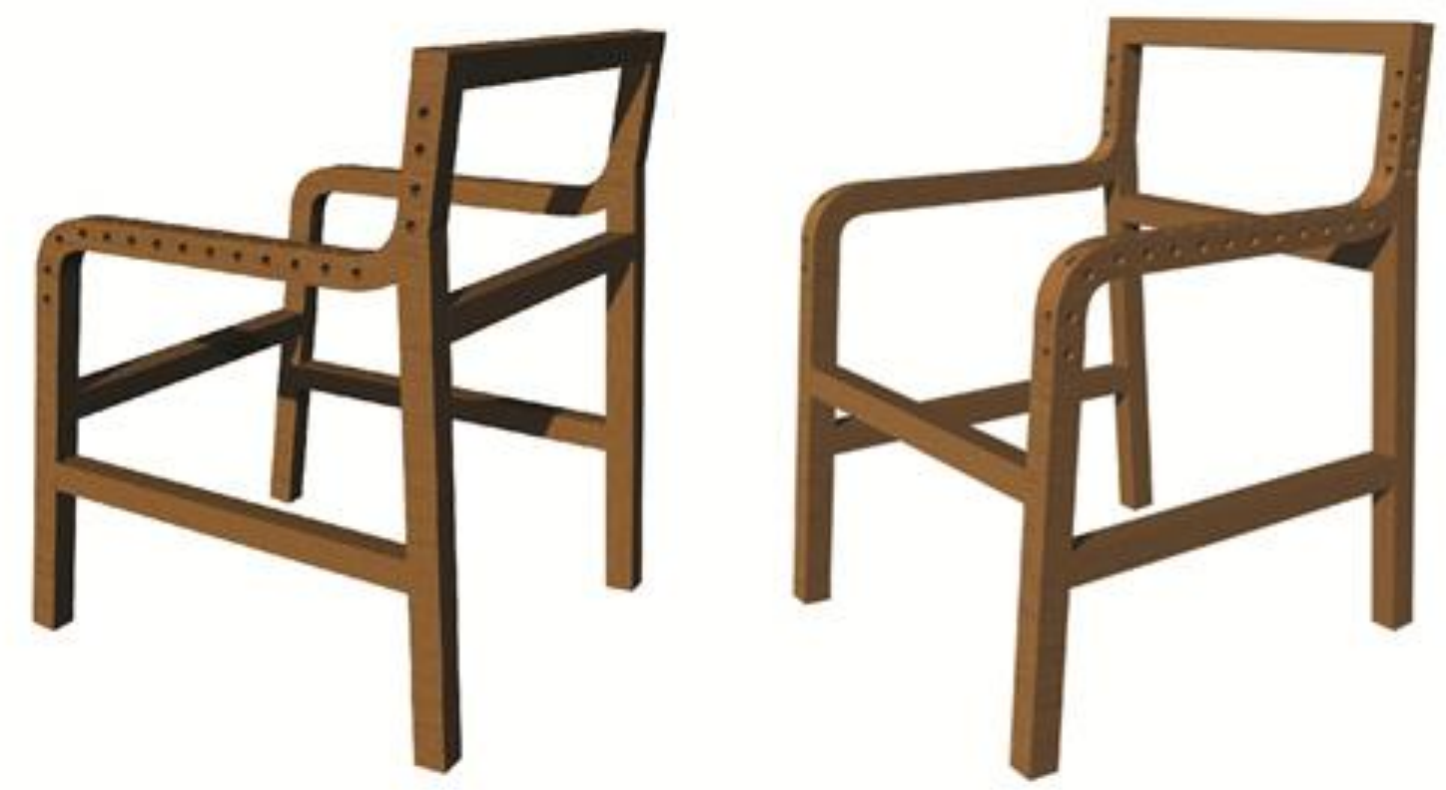

Gambar 10. Desain Rangka terpilih
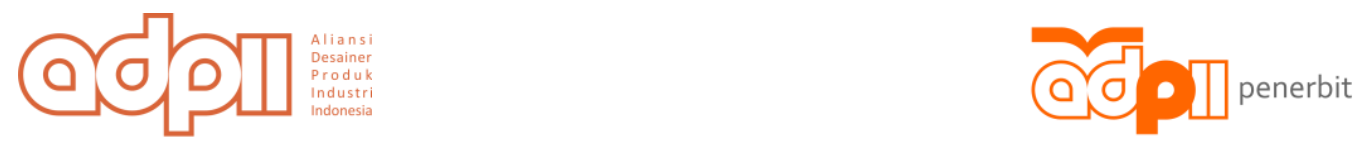


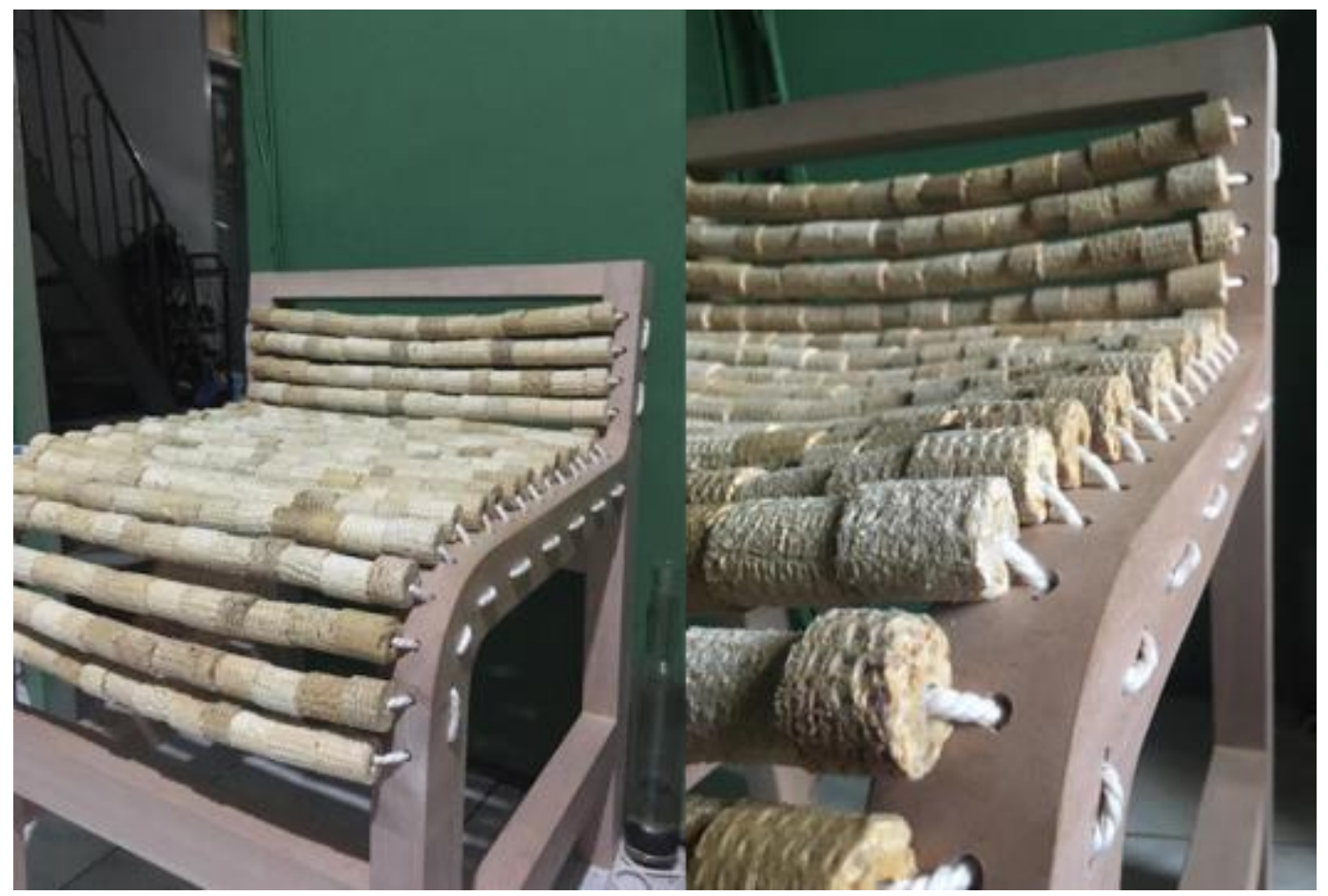

Gambar 11. Prototype Eksperimen Jointing Anyaman Pada Kerangka Kursi

Eksperimen selanjutnya yaitu uji ketahanan tali dan modul silnder saat sudah menjadi alas duduk. Kursi pertama yang diproduksi memiliki bentuk paling sederhana dan belum mempertimbangkan aspek ergonomi. Kerangka masih bersifat polos dan belum mempertimbangkan pertemuan kerangka dengan jointing anyaman. Pada eksperimen ini tali hanya diikatkan pada kerangka kursi..

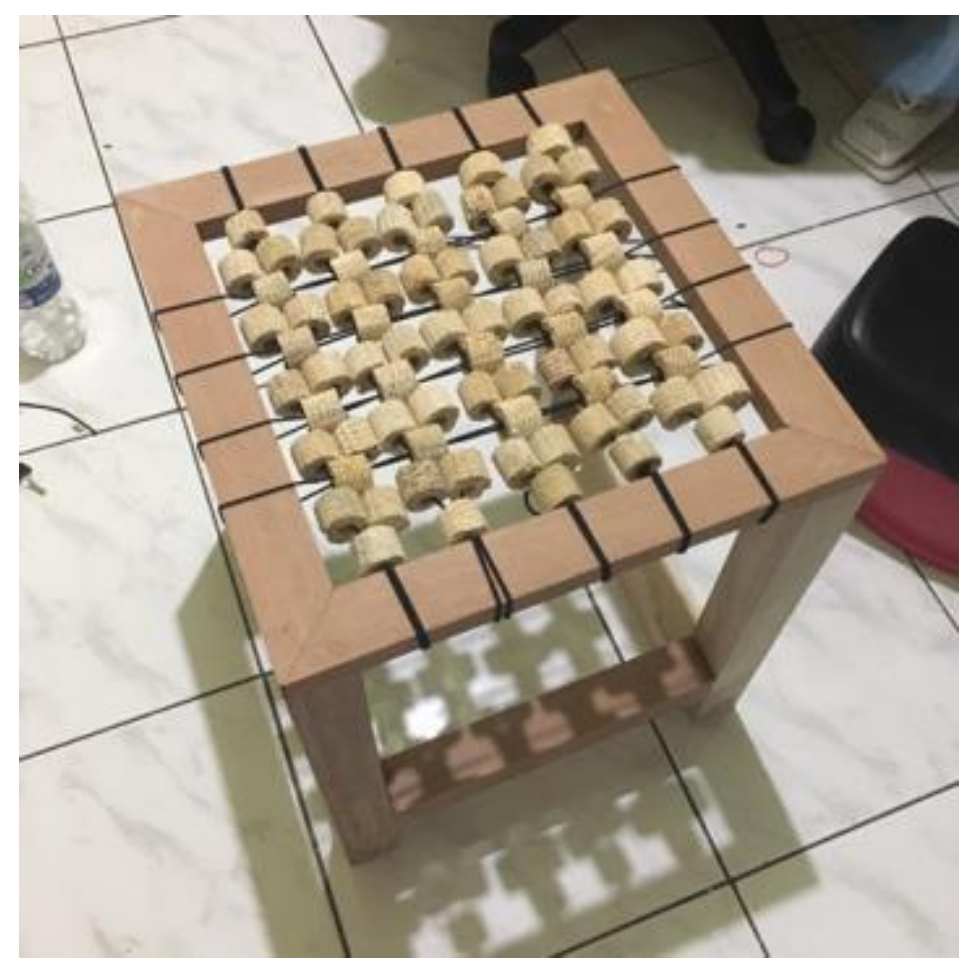

\section{Gambar 12. Eksperimen Kursi I}

Kursi kedua diproduksi dengan desain yang dilengkapi detail untuk jointing dan perhitungan lebar alas duduknya.
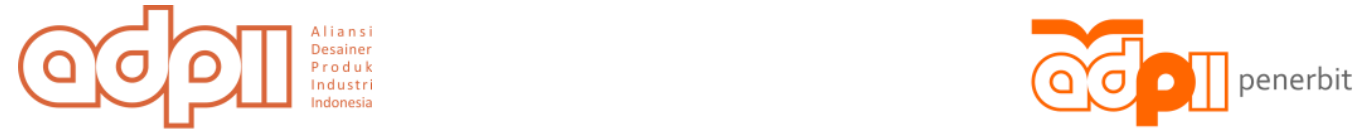


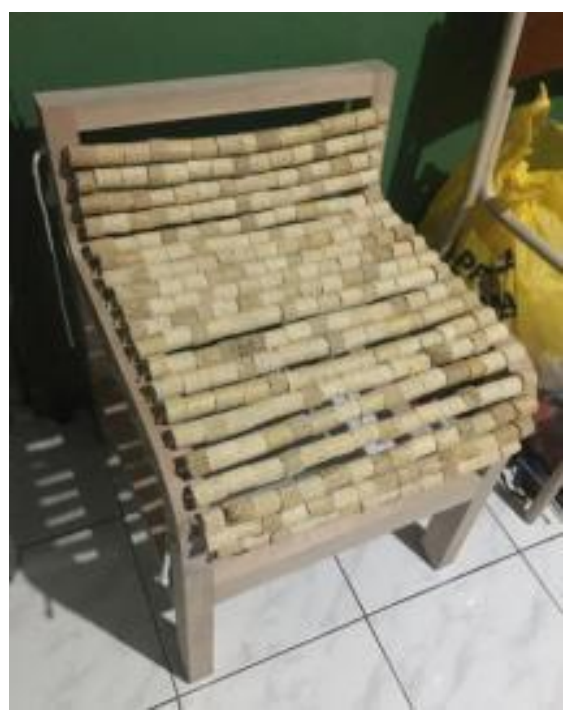

Gambar 13. Eskperimen Kursi II (Protorype Awal)

Eksperimen kursi II di atas teranalisis bahwa modul bonggol jagung memiliki diameter yang berbedabeda walaupun panjang bonggol jagung sudah seukuran. Akibat dari berbedanya diameter bonggol jagung, ketika dianyam dengan tali bonggol akan terlihat tidak rapih karena diameternya berbeda-beda. Maka, dibutuhkan bonggol dengan diameter yang sama, sehingga harus melewati proses pemilahan lagi.

Kursi 2 sudah diuji coba diduduki. Dari hasil analisis, anyaman tali dengan bonggol terbukti kuat untuk diduduki namun bonggol yang terhimpit tali dan kayu rentan hancur karena bonggol sendiri tidak kuat menahan beban apabila terhimpit benda keras. Hasil analisis juga menunjukkan visual jointing tali pada kerangka kursi kurang bagus dilihat sehingga menurunkan aspek estetika pada kursi.

\section{KESIMPULAN}

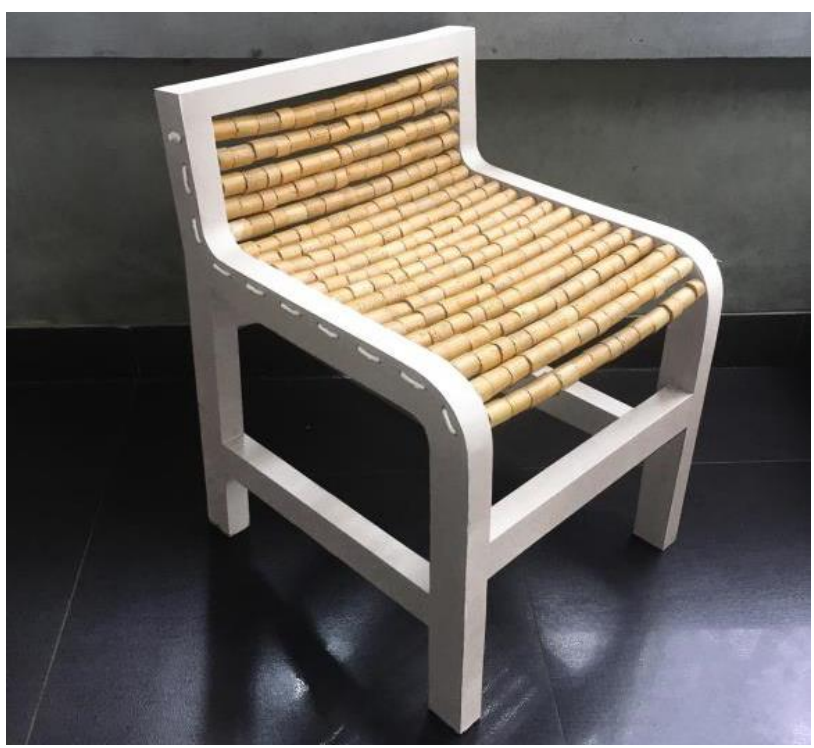

\section{Gambar 14. Prototype}

Beberapa keputusan dalam proses pemanfaatan modul bonggol jagung sebagai bahan baku adalah penggunaan dempul kayu untuk memperoleh kualitas permukaan yang baik sebagai produk fungsional.
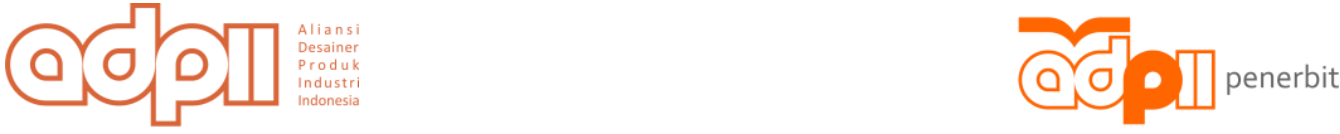
Penggunaan dempul dinilai tepat sehingga tekstur bonggol jagung tetap terlihat sehingga karakteristik bonggol jagung tidak hilang.

Keputusan untuk jenis tali yang dipakai adalah tali tambang berukuran $5 \mathrm{~mm}$ dengan pertimbangan tali tambang dikenal kuat dan ukurannya yang sesuai dengan diameter dalam modul bonggol jagung. Tali tambang ini termasuk kuat menahan beban, namun akan semakin renggang ketika diduduki, sehingga harus melewati beberapa kali uji coba beban pada alas duduk dan penarikan kembali tali yang renggang hingga tali berhenti merenggang, karena tali tambang yang baru dipakai belum sepenuhnya tertarik sehingga tali akan terus merenggang. Hal ini merupakan kekurangan pada jenis tali yang dipilih dan berdampak pada anyaman bonggol jagung.

Keputusan untuk pertemuan rangka kursi dengan jointing anyaman diubah dari eksperimen prototype awal kursi, karena visual kursi yang terlihat kurang bagus dan berpengaruh kepada modul bonggol jagung yang terletak di atas kayu dan terhimpit dengan tali sehingga mengakibatkan modul mudah hancur. Maka dari itu jointing anyaman dibuat sejajar dengan rangka kursi agar terlihat lebih rapih dan tidak merusak modul bonggol.

Dalam segi rangka kursi, kekurangan terdapat pada bagian sandaran kursi, karena user tidak bersandar ke bonggol jagung melainkan ke rangka kayu, hal tersebut tidak memaksimalkan peran bonggol jagung sebagai sarana duduk.

Hasil dari penelitian ini adalah kursi dengan modul bonggol jagung berbentuk silinder sebagai komponen utama pada alas duduk. Produk yang dihasilkan membuktikan bahwa bonggol jagung dapat dimanfaatkan sebagai salah satu bahan baku bagi komoditas yang memiliki nilai kebaruan.

Diperlukan penelitian lebih lanjut mengenai keterserapan pasar dan penetapan harga produksi untuk komoditi kursi berbahan baku bonggol jagung.

\section{DAFTAR PUSTAKA}

Andry, Agus Sachari, and Pribadi Widodo. "Eksplorasi Material Bonggol Jagung untuk Mendapatkan Nilai Kebaruan pada Produk Kerajinan Kreatif." 2015: 3.

Andry, and Martinus Pasaribu. Craft dan Desain di Indonesoa sudut pandang akademik dan pelaku. Bandung: Aliansi Desainer Produk Industri Indonesia, 2018.

Dedy, Ismail. "Uji fisik bonggol jagung olahan sebagai alternatif bahan baku dalam konsep produk fungsional." jurnal rekayasa, 2011: 3.

Mahardhika, Farida Ratna D. "Analisis Pengembangan Usaha Pemanfaatan Limbah Bonggol Jagung Menjadi Produk Kerajinan Multiguna." Jurnal Manajemen dan Organisasi, 2014.

mareta, Fransisca. $\quad$ Kompasiana. November 2018. https://www.kompasiana.com/fransiscamks/5be6f54aaeebe12b241de9ad/limbah-tongkoljagung-disulap-menjadi-tepung (accessed November 20, 2019).

Siang, Teo Yu. Interaction Design Foundation. n.d. https://www.interactiondesign.org/literature/article/5-stages-in-the-design-thinking-process (accessed 0107,2020 ).
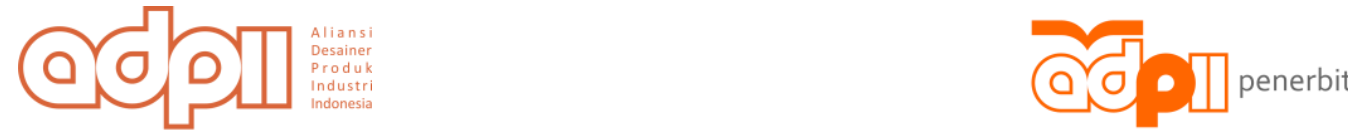